\title{
Acute Occlusion of Right Femoral Artery Resulting in Gangrene of Right Leg Due to Essential Thrombocythemia and Atherosclerosis in COVID-19 era: A Case Report
}

\author{
${ }^{2}$ Department of Haematology, Defence Services General Hospital, Myanmar \\ ${ }^{3}$ Department of Physician, Defence Services General Hospital, Myanmar \\ ${ }^{4}$ Department of Physician, Defence Services General Hospital, Myanmar \\ ${ }^{5}$ Department of Physician, Defence Services General Hospital, Myanmar \\ ${ }^{6}$ Department of Physician, Defence Services General Hospital, Myanmar \\ ${ }^{7}$ Department of Haematology, Defence Services General Hospital, Myanmar \\ ${ }^{8}$ Department of Physician, Defence Services General Hospital, Myanmar \\ ${ }^{9}$ Department of Physician, Defence Services General Hospital, Myanmar \\ ${ }^{10}$ Department of Physician, Defence Services General Hospital, Myanmar
}

Khin Phyu Pyar ${ }^{1 *}$, Aung Aung' ${ }^{2}$ Kaung Myat ${ }^{3}$, Kyaw Ko Ko Aung ${ }^{4}$,Thein Soe Tun ${ }^{5}$, Win Myint ${ }^{6}$, Kyaw Zaya ${ }^{7}$, Myo Thant Kyaw $^{8}$, Zay Phyo Aung ${ }^{9}$ and Nyan Naing Soe ${ }^{10}$

${ }^{1}$ Department of Medicine and Nephrology Defence Services Medical Academy, Defence Services General Hospital, Myanmar

*Corresponding author: Khin Phyu Pyar, Department of Medicine and Nephrology Defence Services Medical Academy, Defence Services General Hospital, Myanmar.

To Cite This Article: Khin Phyu Pyar, Aung Aung, Kaung Myat, Kyaw Ko Ko Aung, Thein Soe Tun, et al., Acute Occlusion of Right Femoral Artery Resulting in Gangrene of Right Leg Due to Essential Thrombocythemia and Atherosclerosis in COVID-19 era: A Case Report. Am J Biomed Sci \& Res. 2021 - 12(6). AJBSR.MS.ID.001804. DOI: 10.34297/AJBSR.2021.12.001804.

Received: 眥 April 27, 2021; Published: 眥 May 11, 2021

\footnotetext{
Case Summary

A 43-years old man, chronic heavy smoker, had sudden onset of severe pain in right leg. He was hypertensive and had cerebrovascular accident with right hemiparesis 10 years ago. He had absent right femoral artery pulsation. His right leg was swollen, discolored, cold and gangrenous. He underwent amputation of right leg, above knee at upper thigh. He was found to have essential thrombocythemia and atherosclerosis.
}

\section{Introduction}

The incidence of acute limb ischaemia is rare and is estimated to be 14 per 100,000 population [1]. The arterial occlusion is caused by several pathology: thickening of arterial wall - atherosclerosis; inflammation of arterial wall - vasculitis; hypercoagulable state protein $\mathrm{C} / \mathrm{S}$ deficiency; and thrombo-embolism - atrial fibrillation. Acute arterial occlusion is one of the vascular emergencies and it is more likely to be due to thrombo-embolic phenomenon.
Occlusion of a large artery may result from atherosclerosis and large vessel arteritis like Takayasu's arteritis. The common diseases giving rise to hypercoagulable state are protein $\mathrm{C} / \mathrm{S}$ deficiency, factor 5 Leiden deficiency, hyper-homocystinemia, paroxysmal nocturnal haemoglobinuria, malignancy, DIC, infection and essential thrombocythemia.

Essential thrombocythemia is an indolent myeloproliferative 
neoplasm that may be complicated by vascular events, including both thrombosis and bleeding. It may present with occlusion of vessels; half of them causes microvascular occlusion [2] and occlusion of major artery is not common. There are few case reports on essential thrombocythemia causing acute arterial obstruction at brain [3], heart [4,5] and limbs [6]. Some cases of essential thrombocythemia have recurrent thrombosis $[7,8]$.

Acute limb ischemia of the lower extremity is a potentially devastating condition that requires urgent and definitive management. The main strategy in managing acute arterial obstruction is "to save the limb/organ". Anticoagulation is the main stay of treatment and several measures like in situ thrombolysis and surgical intervention are tried. On-going obstruction with maximum anticoagulation and development of gangrene are the only indication for amputation. According to [1], patients presenting with acute limb ischaemia have a 30-day amputation rates of $10 \%$ to $30 \%$ and a mortality rate of around $15 \%$.

\section{Presentation}

A 43-year-old man had sudden onset of severe pain in right leg. He noticed that his whole leg looked pale and it was cold initially, and it later turned to brown color. He could neither move nor feel his leg. He came from the very remote area and referred to our hospital on day 7 after symptom onset. He was a chronic heavy smoker and has hypertension and had cerebrovascular accident with right hemiparesis 10 years ago. He smoked 4 cheroots per day for 30 years. Firstly, COVID-19 infection was excluded. His blood pressure was $170 / 100 \mathrm{mmHg}$ on admission. He was apyrexial. He had features of acute arterial occlusion with gangrene of right leg: swollen black discolorations up-to upper thigh, large areas of ecchymosis, skin necrosis and ulceration over calf, cold on touch, blisters, molting and putrefaction extended up to knee, gangrene of toes, both sensory and motor loss, and absent dorsalis pedis pulse, popliteal pulse and femoral pulse. (Figure $1 \& 2$ ) The remaining pulses in both upper limb and left leg were normal and in sinus rhythm. Examination of heart was normal. Doppler ultrasound showed absent arterial flow in right popliteal and femoral artery. Echocardiogram was normal.

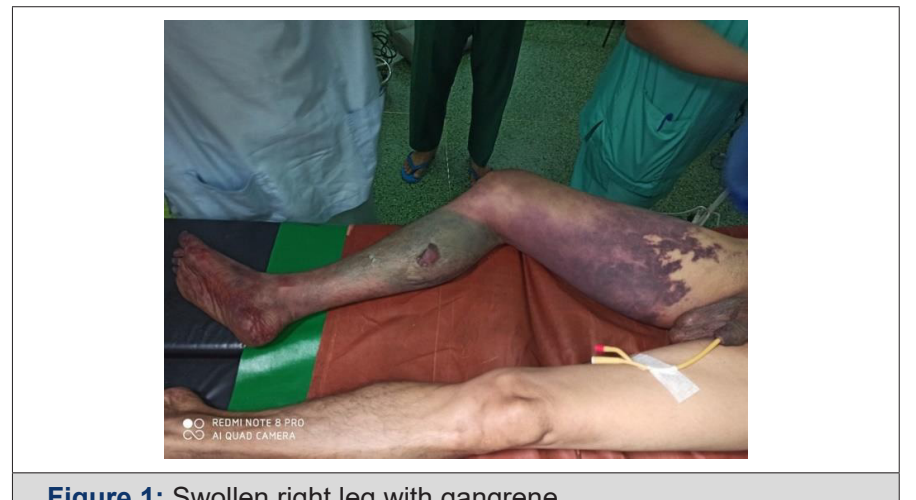

Figure 1: Swollen right leg with gangrene.
He underwent thrombo-embolectomy, amputation of right leg, above knee at upper thigh as anti-coagulation failed and the limb was gangrenous (Figure $3 \& 4$ ). Ten days later, wound debridement and bone shortening was done and two weeks later, wound was closed after shortening of bone again.

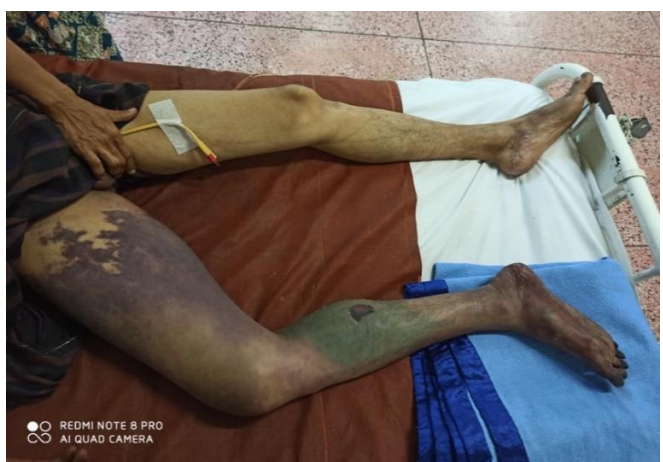

Figure 2: Swollen right leg with gangrenous ulcer over calf and gangrene of toes.

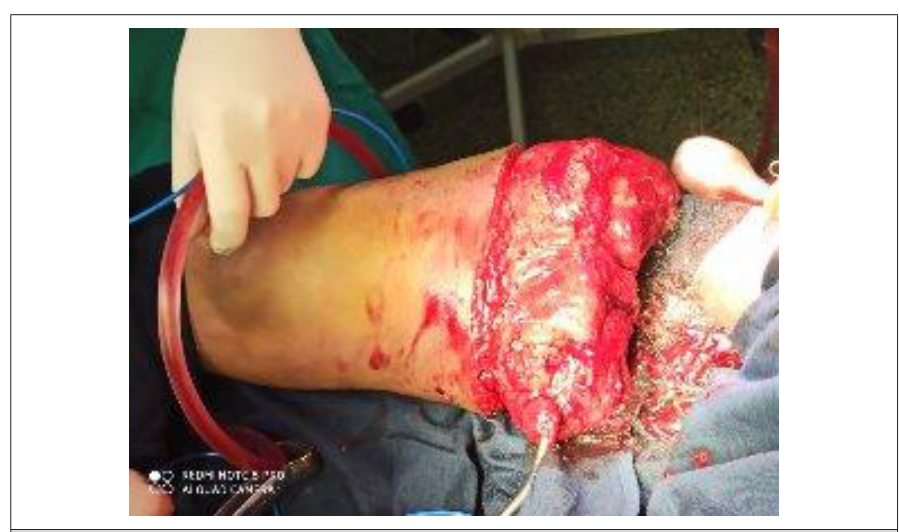

Figure 3: Above knee amputation (upper thigh).

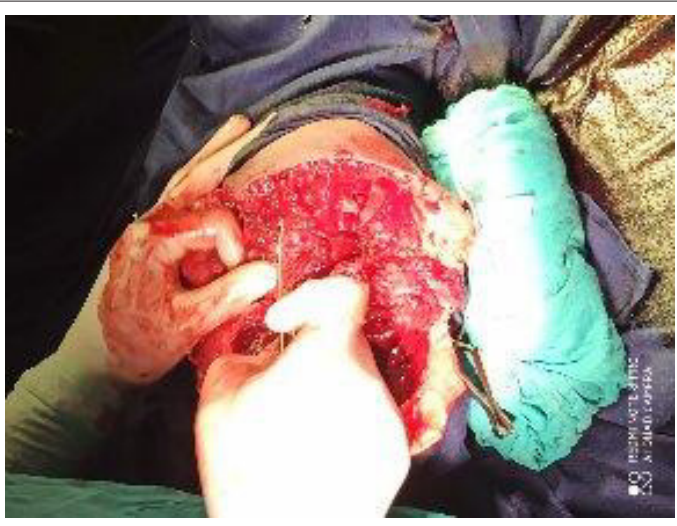

Figure 4: Above knee amputation (upper thigh).

As his left femoral artery pulsation became weak and thus, CT Aortogram was done (4 weeks after symptom onset of right femoral artery occlusion). It revealed extensive thrombosis with complete obstruction of abdominal aorta starting below the level of celiac trunk- both renal arteries and both iliac arteries. The calcifications of the arterial wall at aortic arch, thoracic and abdominal aorta and both iliac vessels were seen too. (Figures 5-11) Thus, he had 
severe atherosclerosis due to hypertension and heavy smoking Occlusion of both renal arteries explained his high blood pressure. The cholesterol and uric acid level were normal. He was treated with atorvastatin, aspirin, clopidogrel, antihypertensives, wound care, physiotherapy, intensive nursing care nutritional support and antibiotics.

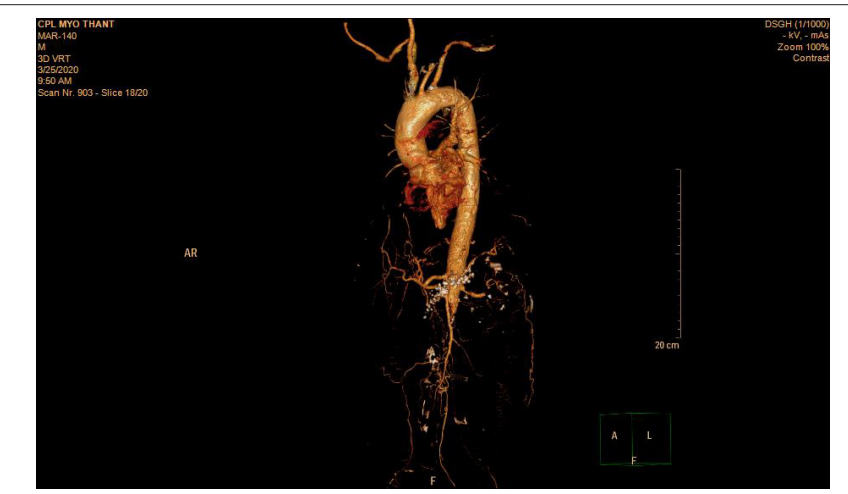

Figure 5: Aortic wall calcification \& obstruction - tapering above origin of renal arteries.

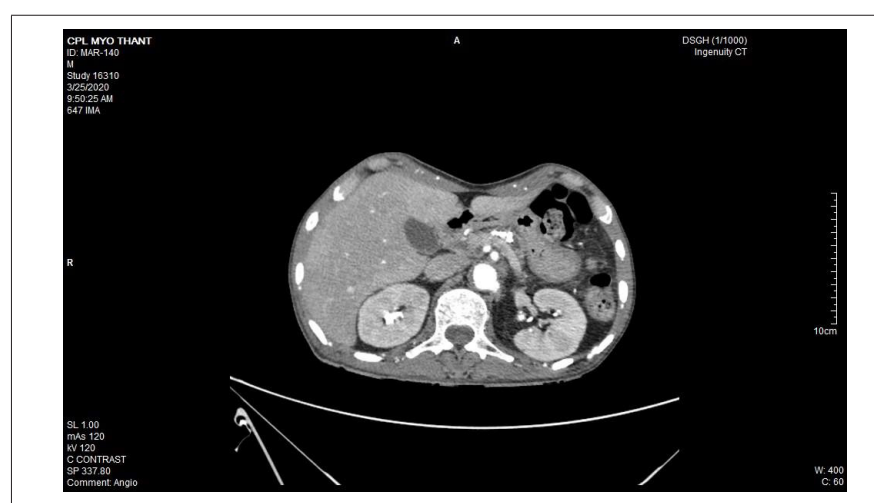

Figure 6: CT aortogram showing occlusionof aorta after celiac trunk.

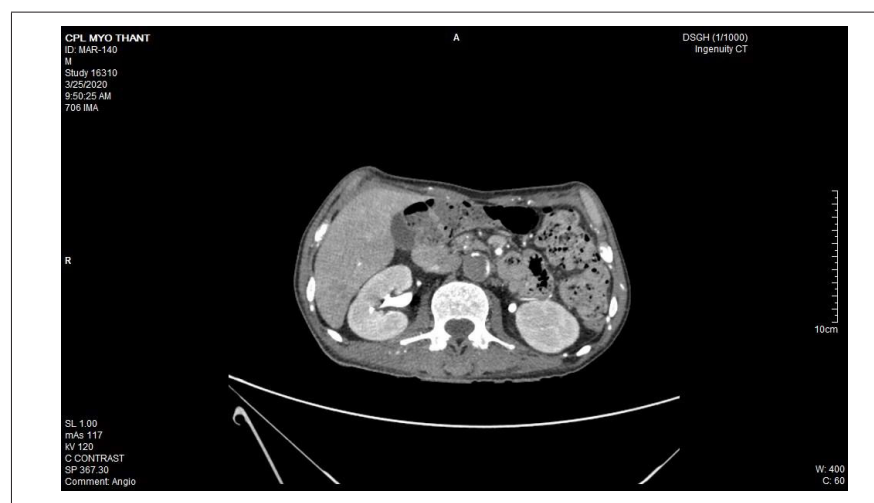

Figure 7: CT aortogram showing occlusion at the origin of right renal artery.

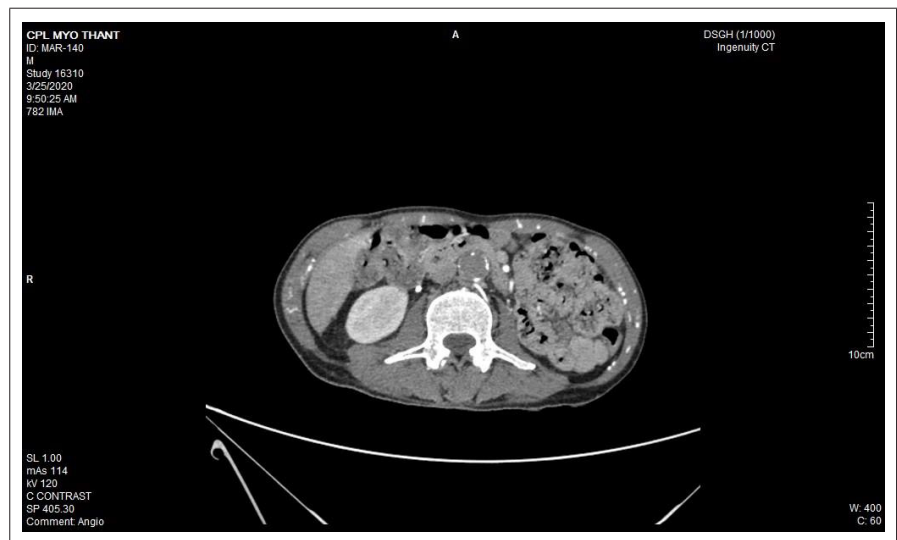

Figure 8: CT aortogram showing thrombus filled aorta with wall calcification.

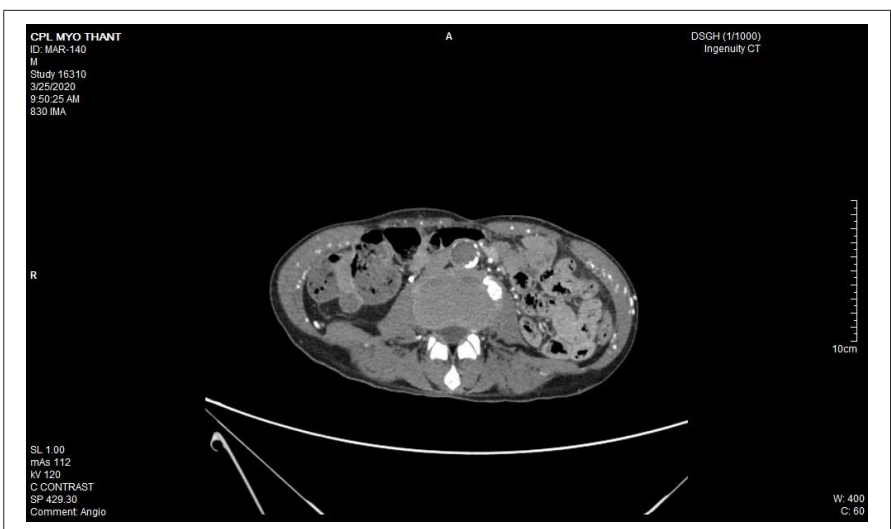

Figure 9: CT aortogram showing thrombus filled aorta with wall calcification.

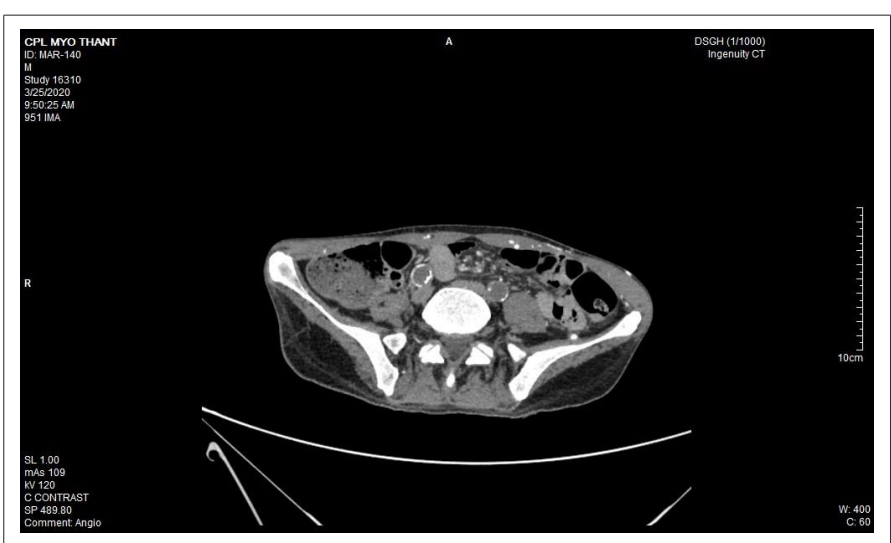

Figure 10: CT aortogram showing complete occlusion of both iliac arteries. 


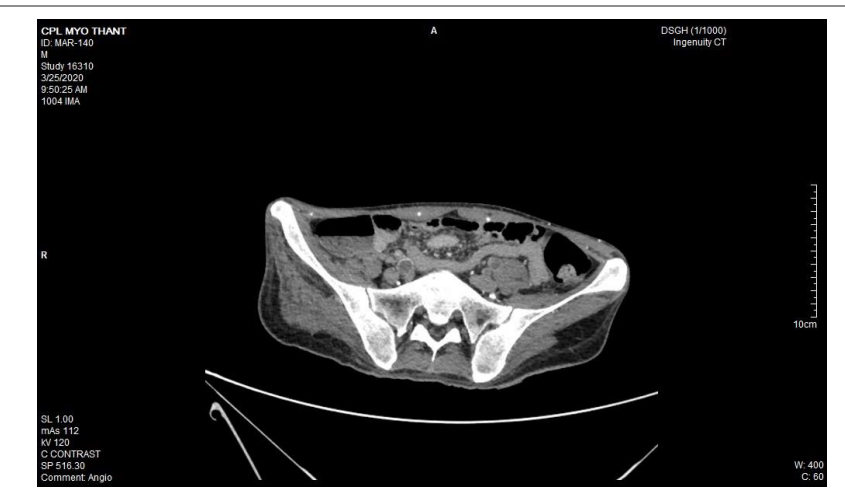

Figure 11: CT aortogram showing complete occlusion of both iliac arteries.
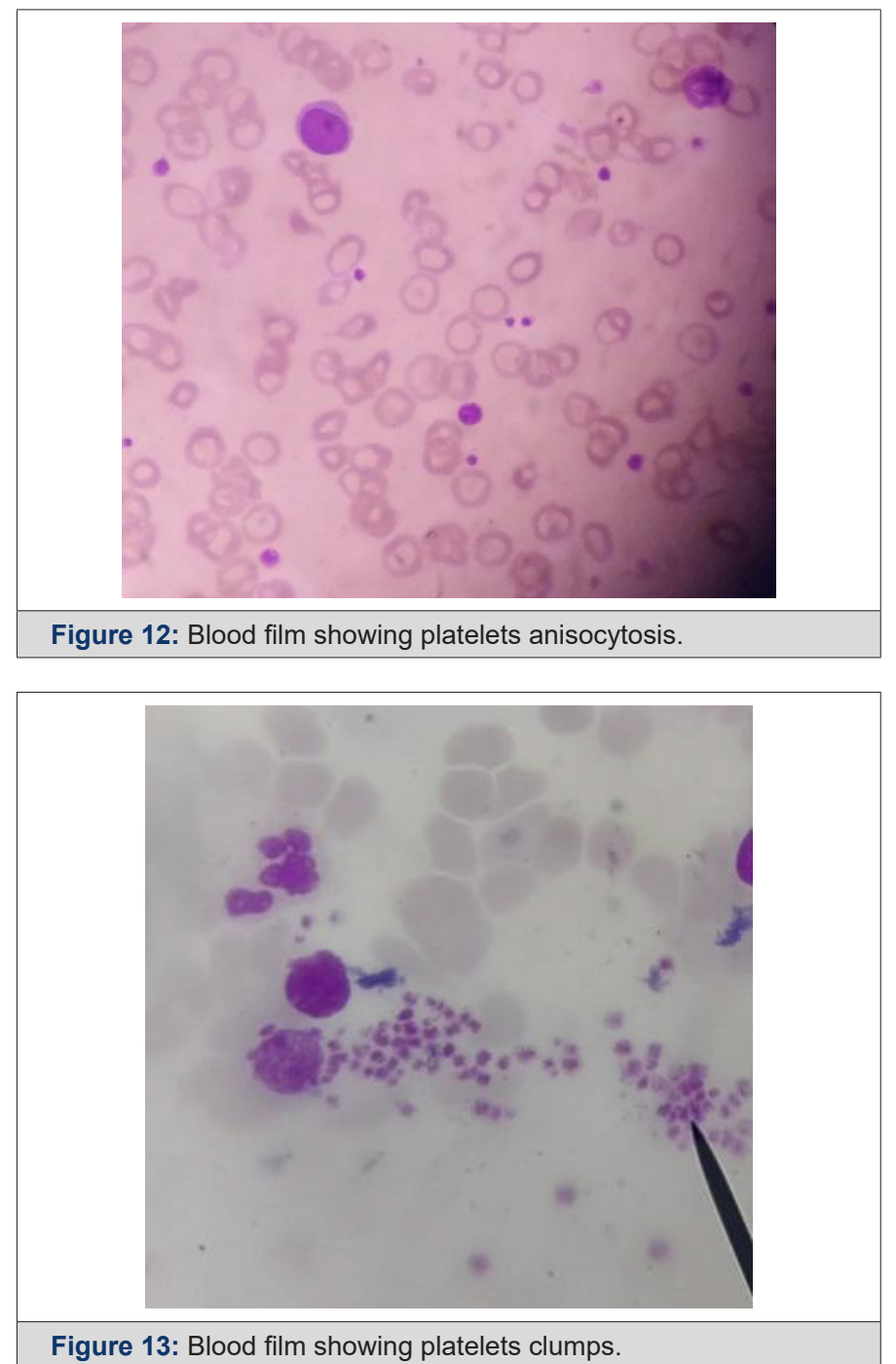

His initial blood for complete picture was as follows; haemoglobin $12.6 \mathrm{~g} \%$, neutrophil leucocytosis (total WBC $20.0 \mathrm{X}$ 109/L, Neutrophils 80\%) and platelets 123 X10 $/$ L. Two weeks later, his platelets count increased to $505 \times 10^{9} / \mathrm{L}$ and total $\mathrm{WBC}$ rose to $32.2 \times 10^{9} / \mathrm{L}$. One month later, there was further rise in platelets count increased to $840 \times 10^{9} / \mathrm{L}$ though both haemoglobin and total WBC count fall to $8.3 \mathrm{~g} \%$ and $14.5 \times 10^{9} / \mathrm{L}$ respectively. The drop in total WBC indirectly indicated that infection was fairly controlled. However, falling haemoglobin and very high platelet count were striking. Therefore, the treating surgical team consulted with haematologist and he noticed neutrophil leucocytosis and thrombocytosis with clumps of platelets in the blood film. Platelet anisocytosis with some atypical large platelets were seen too (Figure 12\&13). In view of high blood LDH 283 U/L (140-280), high serum globulin 51 g/L (20-35) and severe atherosclerosis with thrombosis, the possibilities were as follows:(a) autoimmune disease like SLE, RA, Antiphospholipid syndrome; (b) lymphoproliferative disease such as lymphoma, lymphatic leukaemia; and (c) myeloproliferative disease. Thus, he did bone marrow aspiration (8 weeks after symptom onset of right femoral artery occlusion). It revealed abundant megakaryocyte with predominance of large form and deeply lobated and hypersegmented nuclei. Erythroid and granulocyte series were slightly increased. Abnormal dysplastic cell and increased number of blast form were not found (Figure 14). Bone marrow trephine biopsy showed normocellular marrow with several megakaryocytes (Figure 15). Although molecular and cytogenetics studies were not available, presence of typical bone marrow features and extensive arterial thrombosis favored the diagnosis of myeloproliferative disorder most probably essential thrombocythemia.

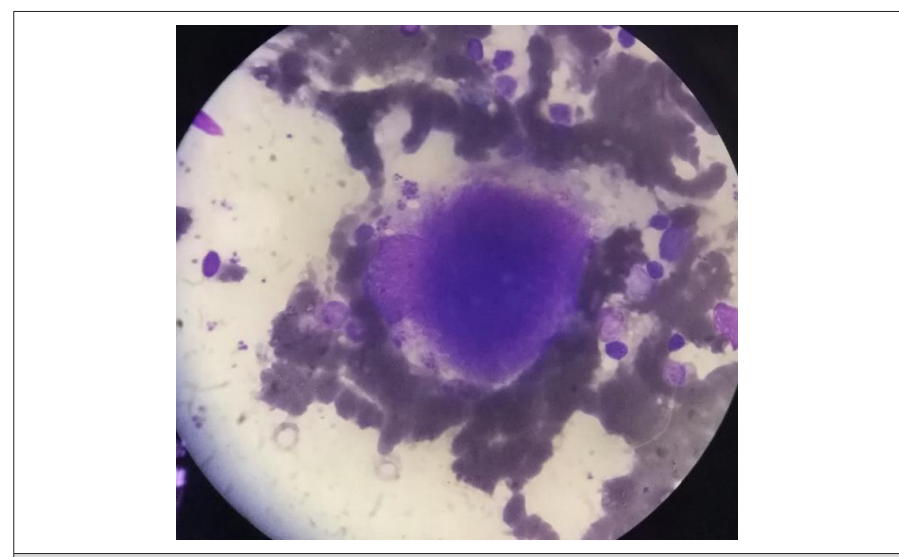

Figure 14: Bone marrow aspiration showing large megakaryocyte with deeply lobated nuclei (X100 view).

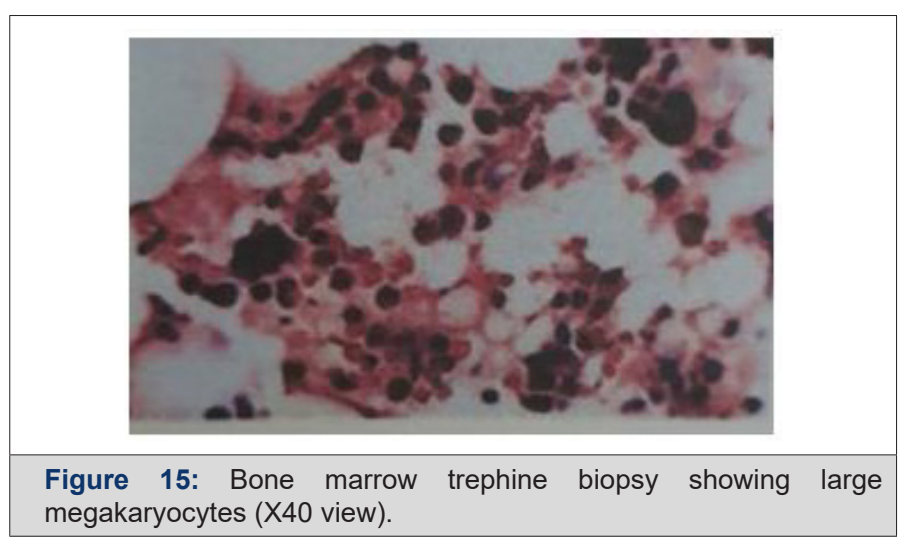


Table 1: Serial haematological parameter.

\begin{tabular}{|c|c|c|c|c|}
\hline $\begin{array}{c}\text { Timing in week } \\
\text { (Symptom onset of right } \\
\text { femoral artery occlusion) }\end{array}$ & Haemoglobin(g\%) & Total WBC $\left(\mathrm{X} 10^{9} / \mathrm{L}\right)$ & Platelets (X10 $\%$ L) & Remark \\
\hline Week 1 (on admission) & 12.6 & 20.0 & 123 & \\
\hline Week 2 & 12.5 & 32.2 & 505 & \\
\hline Week 3 early & 8.3 & 14.5 & 840 & Haematologist blood film \\
\hline Week 3 late & 10.0 & 12.7 & 715 & Bone marrow \\
\hline \multicolumn{5}{|l|}{ Week 4} \\
\hline Week 5 & 8.4 & 17.1 & 658 & \\
\hline \multicolumn{5}{|l|}{ Week 6} \\
\hline Week 7 & 9.4 & 20.0 & 971 & \\
\hline \multicolumn{5}{|l|}{ Week 8} \\
\hline Week 9 & 8.4 & 15.0 & 1140 & \\
\hline Week 10 & 10.9 & 3.5 & 625 & \\
\hline Week 11 early & 10.7 & 1.2 & 337 & \\
\hline Week 11 late & 9.1 & 1.3 & 103 & \\
\hline
\end{tabular}

Bone marrow report was compatible with "Essential thrombocythemia" and suggested to exclude chronic inflammation and other secondary causes. (Figure 16 \& 17) His prothrombin time was 19.5 seconds; INR was 1.78 and APTT was 41.7. D dimer level was $0.4 \mathrm{mg} / \mathrm{dl}$. PNH was excluded as sugar water test and heat resistance test were negative. Anti-phospholipid syndrome was not possible as "Lupus Anticoagulant" (1.2) and "Anti Cardiolipin Ig G" (3.98) were negative. The "b2 Glycoprotein Ig G" (9.20) was also negative.

Therefore, he was a case of "Essential thrombocythemia causing severe arterial thrombosis and previous cerebro-vascular accident". Thus, the patient was put on Hydroxyurea (7 weeks after symptom onset of right femoral artery occlusion). Two weeks later, the platelet count reduced dramatically to $337 \mathrm{X} 10^{9} / \mathrm{L}$ though leucopenia set in (total WBC $1.2 \mathrm{X} 10^{9} / \mathrm{L}$ ). His clinical condition was deteriorating and he had opportunistic infections- oral candidiasis. The aspiration pneumonia was troublesome and the wound were gaping. At last, we could not save the patient and he expired 11 weeks after symptom onset of right femoral artery occlusion.

\section{Discussion}

The two principal etiologies of acute ischemia of the lower limbs are arterial embolism and in situ thrombosis of an atherosclerotic artery [9]. The main strategy in managing acute arterial obstruction is "to save the limb/organ". Anticoagulation is the corner stone of treatment. On-going arterial obstruction with maximum anticoagulation and development of gangrene are the only indication for amputation. According to the study done in Hong Kong, factors favoring higher amputation rate in patients presenting with acute arterial occlusion were male sex, smoking and intravenous drug abuse [10]. This patient came to hospital quite late - day 7 after symptom onset as he was living in very remote area. His right leg was almost dead with florid gangrene and thus emergency embolectomy with amputation was done to save the life. Thus, awareness among public and health care personnel is important for early recognition and management of acute limb ischaemia [10].

This patient had on going ischaemia as the wound was not healing well and diminished left femoral pulsation. And it was a clinical clue to arterial obstruction at higher level - above femoral artery. It was proved by CT angiogram.

Regarding the aetiology of arterial occlusion in this 43-year-old patient, relatively young age, severe atherosclerosis was the main culprit as there were extensive atheromatous plaque in wall of the whole aorta and it was aggravated by smoking and hypertension. It was the main reason for reporting this case. Moreover, It was not due to COVID-19 infection because it was excluded initially though there were few case reports having deep vein thrombosis, pulmonary embolism and arterial thrombosis due to COVID-19 infection [11-13].

The clue to essential thrombocythemia was from blood picture done in day 21 symptom onset of right femoral artery occlusion because initial thrombocytosis was regarded as reactionary. It again highlighted the importance of interpretation of full blood count. Presence of high platelet count and platelets clumps in blood film and bone marrow examination gave the final diagnosis although we could not perform genetic markers. Thorough examination of blood 
film and bone marrow examination were essential in developing country like us as doing genetic markers were expensive. It was also another reason for presenting this rare case.

In essential thrombocythemia, recurrent thrombosis of same artery was seen in some cases $[7,8]$. Moreover, thrombosis at multiple site was reported too [14,2]. It commonly causes obstruction of small vessels and rarely to median and large arteries. Nevertheless, there were reports on essential thrombocythemia producing thrombosis of aorta [15-17]. In this case, combination of hypertension, smoking, severe atherosclerosis and essential thrombocythemia gave rise to extensive thrombosis of aorta; the rare variety of this case.

In view of treatment of essential thrombocythemia; cytoreductive drugs- hydroxyurea mainly for older patients, and interferon $\alpha$ primarily for younger patients [18]. This case can be classified as high risk because the clinical presentation is large artery thrombosis [19] though JAK2/MPL mutations is not known. Combination of asprin and hydroxyurea is indicated as this patient had thrombosis [20]. If platelets count is more than 2,000 X 109/L, thrombocytophresis may be helpful [21-23]. Because of combination of poor prognostic factors; immune dysfunction in essential thrombocythemia itself , overwhelming septicaemia, and side effects of hydroxyurea - leucopenia, the patient died from opportunistic infection.

\section{Conclusion}

In acute ischaemia of limb, early diagnosis and management is important to save the limb as well as the life of patient. Atherosclerosis is the major risk factor for thrombosis. Combination of more than one risk factor for arterial occlusion - atherosclerosis, hypertension, smoking and essential thrombocythemia leads to extensive massive occlusion of large artery -aorta. Clinical presentation, awareness of platelet count in full blood count and platelet morphology in blood film give a clue to early diagnosis of essential thrombocythemia.

\section{Acknowledgements}

The authors would like to thank the patient >s family for giving consent to this article. Also, to all doctors and nursing team for making great efforts in caring him. The authors acknowledged the following team; Professor Hla Aung for orthopedic care, Dr Yan Naung \& Dr Kyaw Thura for vascular surgery, Professor Yu Aye Latt for intensive care, Professor Tin Moe Mya for laboratory support, Professor Ko Ko Lwin, Professor Kyaw Zay Ya and Professor Myint Zaw for administrative support.

\section{Conflict of Interest}

The authors declared no potential conflicts of interests with respect to authorship and publication of this article.

\section{References}

1. Dormandy J, Heeck L and Vig S (1999) Acute limb ischemia. Seminars in Vascular Surgery 12(2): 148-153.

2. Rospond Kubiak I, Oszkinis G, and Kocięcki J (2016) Retinal Intraarterial Thrombocytic Material Revealing Essential Thrombocythemia. JAMA Ophthalmology 134(8): e161111-e161111.

3. Adrià A, Carles B, Pilar A, Massons JB, Lourdes F, et al. (1995) Ischemic Stroke as First Manifestation of Essential Thrombocythemia. Stroke 26(8): 1463-1466.

4. Alioglu, E, Tuzun, N, Sahin F, Kosova B, Saygi S, et al. (2009) Non STsegment elevation myocardial infarction in patient with essential thrombocythemia. Thrombosis Journal 7(1): 1.

5. Camacho FJ, Hernández N, Díaz E, and Vázquez R (2009) Essential Thrombocythemia and Acute Myocardial Infarction. Revista Española de Cardiología (English Edition) 62(5): 583-585.

6. Messiha D, Kleinhans M, Rammos C, Dissemond J, Rassaf T, et al. (2021) A Case of Critical Essential Thrombocythemia Complicated by Severe Lower-Extremity Arterial Disease. AJCR 22.

7. Jung SM, and Jun H (2019) Recurrent thrombosis of splanchnic and lower extremity arteries with essential thrombocythemia. SAGE Open Medical Case Reports 7.

8. Geng Y, Chen Z, Dai L, Liu G, and He X (2020) Recurrent arterial thrombosis of the lower extremity with secondary thrombocythemia due to reperfusion injury. A case report 9(5): 3690-3697.

9. Stanislaw PALFCED1, Michael SED2, Mamta Swaroop FED3 (2020) Acute Arterial Embolism of the Lower Limb. In Embolic Disease. IntechOpen.

10. Yang S, Chu N, Lo C, and Tung W (2013) A Six-Year Observational Study on Acute Limb Ischaemia in a Local Emergency Department in Hong Kong. Hong Kong Journal of Emergency Medicine 20(1): 40-44.

11. Del Castillo García S, Minguito Carazo C, Echarte JC, Rodríguez Santamarta M, González TB, et al (2020) A case report of arterial and venous thromboembolism in a patient with severe COVID-19 pneumonia. European Heart Journal - Case Reports 4(6): 1-6.

12. Bastien W, Bree L, Lucas J, Jonathan T, Afif G et al .(2020) 4 Cases of Aortic Thrombosis in Patients With COVID-19. JACC: Case Reports 2(9): 1397-1401.

13. Angelillis M, De Carlo M, Christou A, Marconi M, Mocellin DM et al. (2021) A case report of multisite arterial thrombosis in a patient with coronavirus disease 2019 (COVID-19). European Heart Journal - Case Reports 5(ytaa339).

14. Richard S, Perrin J, Baillot P, Lacour J and Ducrocq X (2011) Ischaemic stroke and essential thrombocythemia: A series of 14 cases. European Journal of Neurology : The Official Journal of the European Federation of Neurological Societies 18(7): 995-998.

15. Chong BK, Mun D, Kang CH, Park CB and Cho WC (2016) Essential Thrombocytosis-Associated Thromboembolism in the Abdominal Aorta. The Korean Journal of Thoracic and Cardiovascular Surgery 49(5): $397-$ 400 .

16. Barrado P, Cañibano E, Fresnillo B and Requena M (2009) Acute lower limb ischemia in a patient with aortic thrombus and essential thrombocytosis. International Journal of Hematology 90(3): 343-346.

17. Geringer J, Fenderson J and Osswald M (2019) Essential Thrombocythemia Complicated by Occlusive Thrombosis of the Abdominal Aorta. Case Reports in Hematology 9454501.

18. Rumi E and Cazzola M (2016) How I treat essential thrombocythemia. Blood 128(20): 2403-2414.

19. Tefferi A, Vannucchi AM and Barbui T (2018). Essential thrombocythemia treatment algorithm 2018. Blood Cancer Journal 8(1): 2. 
20. Birgegård G, Besses C, Griesshammer M, Gugliotta L, Claire N et al. (2018) Treatment of essential thrombocythemia in Europe: A prospective longterm observational study of 3649 high-risk patients in the Evaluation of Anagrelide Efficacy and Long-term Safety study. Haematologica 103(1): 51-60.

21. Elhassan AM, Alsaud A, Yassin MA, Aldapt M, Riaz L et al. (2020) Thrombocytapheresis in Patient with Essential Thrombocythemia: A Case Report. Case Reports in Oncology 13(2): 675-679.
22. Bhatt H and Singh S (2020) Venous thromboembolism and COVID-19: A case report and review of the literature. Journal of Medical Case Reports 14(1): 188.

23. Price LC, McCabe C, Garfield B and Wort SJ (2020). Thrombosis and COVID-19 pneumonia: The clot thickens. European Respiratory Journal 56(1): 2001608. 